\title{
Multiple invasions in urbanized landscapes: interactions between the invasive garden ant Lasius neglectus and Japanese knotweeds (Fallopia spp.)
}

\author{
Jérôme M. W. Gippet ${ }^{1} \cdot$ Florence Piola $^{1} \cdot$ Soraya Rouifed ${ }^{1} \cdot$ Marie-Rose Viricel $^{1} \cdot$ Sara Puijalon ${ }^{1}$. \\ Christophe J. Douady ${ }^{1} \cdot$ Bernard Kaufmann ${ }^{1}$
}

Received: 5 June 2017 / Accepted: 9 December 2017

(c) Springer Science+Business Media B.V., part of Springer Nature 2017

\begin{abstract}
Urbanized landscapes are the theater of multiple simultaneous biological invasions likely to affect spread dynamics when co-occurring introduced species interact with each other. Interactions between widespread invaders call for particular attention because they are likely to be common and because non-additive outcomes of such associations might induce negative consequences (e.g., enhanced population growth increasing impacts or resistance to control). We explored the invasions of two widespread invasive taxa: the Japanese knotweed species complex Fallopia spp. and the invasive garden ant Lasius neglectus, in the urban area of Lyon (France). First, we investigated landscape habitat preferences as well as co-occurrence rates of the two species. We showed that Fallopia spp. and L. neglectus had broadly overlapping environmental preferences (measured by seven landscape variables), but their landscape co-occurrence pattern was random, indicating independent spread and non-obligatory association. Second, as Fallopia spp. produce extra-floral nectar, we estimated the amount of nectar $L$. neglectus used under field conditions without ant competitors. We estimated that $L$. neglectus collected $150-321 \mathrm{~kg}$ of nectar in the month of April (when nectar production is peaking) in a $1162 \mathrm{~m}^{2}$ knotweed patch, an amount likely to boost ant population growth. Finally, at six patches of Fallopia spp. surveyed, herbivory levels were low (1-6\% loss of leaf surface area) but no relationship between ant abundance (native and invasive) and loss of leaf surface was found. Co-occurrences of Fallopia spp. and L. neglectus are likely to become more common as both taxa colonize landscapes, which could favor the spread and invasion success of the invasive ant.
\end{abstract}

Keywords Multiple invasions · Novel interactions · Extra-floral nectaries · Fallopia spp. · Lasius neglectus

\section{Introduction}

As the globalization of human activities increases species transport worldwide, urbanization concentrates introductions and enhances the secondary spread of exotic species.

Handling Editor: Livy Williams.

Electronic supplementary material The online version of this article (https://doi.org/10.1007/s11829-017-9589-2) contains supplementary material, which is available to authorized users.

Jérôme M. W. Gippet

jgippet@gmail.com

1 Université de Lyon, UMR5023 Ecologie des Hydrosystèmes Naturels et Anthropisés, ENTPE, CNRS, Université Lyon 1, Villeurbanne, 69622 Lyon, France
Urbanized landscapes are therefore the theater of multiple simultaneous biological invasions (Vitousek et al. 1997; Bertelsmeier and Courchamp 2014). However, such multiple invasions are often ignored and studies generally focus on single species invasion dynamics (Kuebbing et al. 2013). Invasive species spreading through the same landscape are likely to co-occur and interact with each other, which can enhance (e.g., by facilitation or mutualism, McNeil and Dick 2014) or mitigate (e.g., by competition, predation or parasitism, Jackson 2015) invasion dynamics (Kuebbing et al. 2013; Henriksson et al. 2016). Identifying such interactions and estimating the effects they might have both on invasive spread throughout landscapes and on the magnitude of impacts constitute a major challenge in the study of biological invasions (Kuebbing and Nunez 2015). In the case of mutualistic or commensalistic interactions, invasive species increase their fitness when they co-occur, relative to when 
they live apart from each other, thereby accelerating spread and intensifying impacts on biodiversity and human activities (e.g., "invasional meltdown" situations (Simberloff and Von Holle 1999) where population growth and spread as well as ecological impacts are increased).

Among mutualistic or commensalistic invasive species interactions, interactions between ants (Formicidae) and plants bearing extra-floral nectaries (EFN) or honeydewproducing insects (such as aphids) are particularly threatening because they are common and can be highly beneficial for both or at least one of the interacting invasive species (Koptur 1992; Marazzi et al. 2013; Aranda-Rickert et al. 2017), which is likely to boost invasive species spread.

Here, we investigated a novel interaction between an invasive EFN bearing plant, the Japanese knotweed species complex (sensu lato Fallopia spp., Decrane and Akeroyd 1988), and an invasive ant, Lasius neglectus (Van Loon et al. 1990), taking advantage of their simultaneous presence in the landscape of the urban area of Lyon (France).

Species of the invasive knotweed complex $F$. japonica, $F$. sachalinensis, and their hybrid $F . \times$ bohemica, are among the most successful invaders of riparian and disturbed areas in North America and Europe (Bailey et al. 2009). Knotweeds, originating from Japan, were introduced in Europe in 1849 in the Netherlands (Bailey and Conolly 2000; Djeddour et al. 2008) and have since spread by multiple modes, i.e., rhizome fragmentation (asexual dispersal) and seeds (sexual dispersal) and using multiple vectors i.e., wind (only for seeds), water and human-mediated dispersal (for seeds and rhizomes) (Bailey et al. 2009; Rouifed et al. 2014). In their native range, knotweeds are protected from herbivorous invertebrates by providing ants of numerous species access to EFNs located at stem nodes (Kawano et al. 1999) inducing ants to patrol the plants and predate on young stages of potential defoliators. This protection was shown to extend mainly to young shoots, as EFNs dry out past the spring growth stage (Kawano et al. 1999) but the induction of nectar production has also been observed in older knotweed shoots undergoing herbivory (Ness et al. 2013). Ants are therefore likely increase the rate of shoot growth and ensure success over competitors (Kawano et al. 1999). L. neglectus, probably originating from Asia Minor and introduced in western Europe in the 1970s (first museum collection record in 1973 in Hungary, Espadaler et al. 2007; Ugelvig et al. 2008), is a widespread invasive ant in Europe, building up large colonies of interconnected nests with numerous queens and low intraspecific aggression (Van Loon et al. 1990). Nuptial flights are not known in this species (Van Loon et al. 1990), and natural colony expansion occurs by the occupation of contiguous habitat over limited distances (2-80 m per year, Espadaler et al. 2007), a process often referred to as colony budding. Secondary spread in this ant therefore occurs solely by human-mediated dispersal through road-building and transportation of potted plants or landscaping materials (Van Loon et al. 1990; Schultz and Seifert 2005). L. neglectus has no strong climatic limitation in Europe compared to other invasive ant species such as Linepithema humile and is predicted to have the largest future potential range among potential invasive ants in France (Bertelsmeier and Courchamp 2014). A recent study in North America demonstrated reciprocally beneficial interactions between Japanese knotweeds and the invasive European red ant (Myrmica rubra) in the experimental presence of introduced herbivores (Ness et al. 2013). Such association has been identified as a facilitation process likely to enhance the invasive success of both invaders and potentially magnifying their impacts by accelerating their landscape spread (Lach 2007). However, Ness et al. (2013) found very limited facilitation between the two species, as natural herbivory levels were very low, and nectar production by knotweeds remained rare outside of herbivore proliferation episodes that induced strong nectar production.

Given the ecological characteristics and the landscape infill abilities of knotweeds and L. neglectus, it appeared necessary to investigate their propensity to co-occur when spreading in the same landscape as well as the nature of their association when they do meet, which have never been reported to date. Here, we explored the invasion patterns of L. neglectus and Fallopia spp. at the landscape scale of the urban area of Lyon (France). First, we estimated L. neglectus and Fallopia spp. co-occurrence rate and overlap of environmental preferences at landscape scale. Because these two species have large distributions (global for Fallopia spp. and European for L. neglectus), limited environmental constraints and common dispersal vectors (human activities), they should demonstrate a high co-occurrence probability and overlapping environmental preferences. Second, we investigated the relationship between $\mathrm{L}$. neglectus and Fallopia $\times$ bohemica, which is the most common taxon of the species complex in our study area. We expected $L$. neglectus to use large amounts of nectar from knotweed EFNs, and $F . \times$ bohemica, in return, to profit from the presence of ants which predate potential herbivores and thus prevent leaf damage (Ness et al. 2013). We consequently measured extra-floral nectar uptake by $L$. neglectus during daytime, as well as knotweed leaf surface loss by herbivory in patches with differing $L$. neglectus abundances.

\section{Methods}

\section{Study area}

The study was conducted in the urban area of Lyon, France, and along the two major sets of transportation infrastructures serving the city (A7 motorway, train and Rhône River to the 
South and West, A43 motorway to the East). In 2009, the population of Lyon was 2,214,000 people covering 6017 $\mathrm{km}^{2}$ (National Institute of Statistics and Economic Studies, http://www.insee.fr). Lyon is located at the confluence of the Rhône and Saône rivers and has a continental climate with Mediterranean influences. Mean temperatures are $3.2{ }^{\circ} \mathrm{C}$ in the coldest month (January) and $21.9{ }^{\circ} \mathrm{C}$ in the warmest month (July), with an annual mean temperature of $12.3{ }^{\circ} \mathrm{C}$. The annual average rainfall is $820 \mathrm{~mm}$ (Infoclimat. fr 2006). Fallopia spp. was introduced in Lyon in 1860 in the municipal botanical garden of the city (F. Piola, personal communication). The inhabitants of Saint-Désirat, a village located $60 \mathrm{~km}$ south of Lyon, remember that they were invaded by ants for the first time in 1995 (presence of thousands of ant workers in houses and electrical devices), which makes it the earliest observation of L. neglectus in the area.

\section{Co-occurrence patterns and environmental preferences overlap}

A presence/absence survey of ants was performed following the method of Roura-Pascual et al. (2009) (Fig. 1). The
Fig. 1 Occurrences of $L$. neglectus (red triangles) and Fallopia spp., (green circles), co-occurrences of L. neglectus and Fallopia spp. (orange squares). Sampling sites where both were absent are indicated by black dots. Locations of the two experimental areas used in this study are indicated by a yellow star for experimental area 1 and a yellow cross for experimental area 2

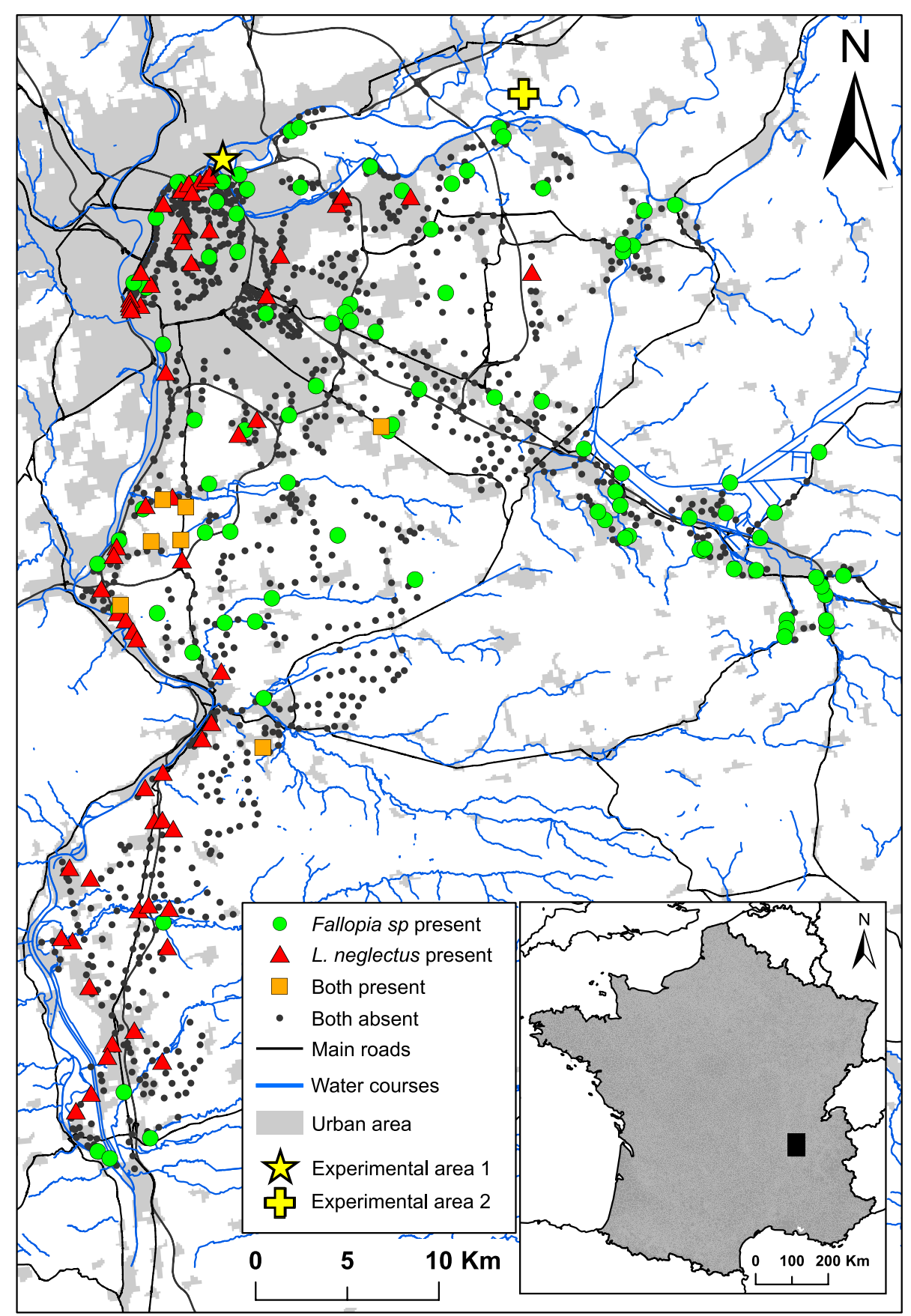


sampling was done during spring and summer 2011-2013, only when air temperatures ranged from 16 to $28^{\circ} \mathrm{C}$ (Seifert 2007). Sampling locations were open vegetation patches, with or without trees and shrubs, and generally close to or along roadsides. They were chosen along road transects, which were selected randomly in the study area, and were located at least $500 \mathrm{~m}$ apart outside the urban core and $200 \mathrm{~m}$ apart inside the urban core. Sampling was performed by teams of 2-5 persons for a cumulative search time of $40 \mathrm{~min}$ (the actual sampling time depended on the number of samplers, e.g., five samplers took 8 min per site; two samplers took $20 \mathrm{~min}$ per site) within a radius of $15 \mathrm{~m}$. Sampling was a direct search of ant nests and trails on the ground, trees and shrubs, followed by hand collecting using an entomological aspirator. Because this sampling survey was designed to detect the two main invasive ant species known in the area (L. neglectus and T. immigrans), only ants from these genera were systematically collected (except for hypogeic Lasius species, see Gippet et al. 2017 for more details). Fallopia spp. occurrences were recorded at each sampling location. Spatial coordinates of the 1248 sampling locations were recorded and imported into ArcGIS v.10.1 (ESRI 2011. ArcGIS Desktop: Release 10.1).

All collected ants were preserved in $96 \%$ alcohol at $-20{ }^{\circ} \mathrm{C}$ and morphologically identified to genus or species whenever possible, following Seifert (2007). One individual per colony of ambiguous Lasius species (i.e., with short or appressed scape setae) was molecularly identified using Cytochrome Oxydase I (COI) sequencing because of complex, error-prone morphological identifications (Seifert 2007).

The association between L. neglectus and Fallopia spp. was tested using co-occurrence analysis (R Core Team 2015, package cooccur; Griffith et al. 2016), with the presence/ absence dataset of each species for each sampling locations ( 0 : absence; 1: presence). The algorithm computes observed and expected frequencies of co-occurrence between the two species (i.e., co-occurrence frequency if species distributions are random and independent from each other). The method is a probabilistic model which returns the probabilities of observing a lower or higher value of co-occurrence than expected by chance with no need for randomizations or null simulations (Veech 2013). We also tested the association between the two invasive species (L. neglectus and Fallopia spp.) and native ant species (Table 1).

Eight environmental variables were chosen to describe main landscape features likely to affect the distribution of the two invasive species (Rouifed et al. 2014; Gippet et al. 2017). We used (i) three land cover variables (proportion of impervious surfaces, agricultural surfaces and forested surfaces in a 500-m radius buffer) informing the landscape context (e.g., urban, agricultural or rural area) and therefore the nature and intensity of human activities which are likely
Table 1 Number of locations where each native species co-occurred with either Fallopia spp. alone, L. neglectus alone or both invasive species

\begin{tabular}{llll}
\hline Native ant species & $\begin{array}{l}\text { Fallopia } \\
\text { spp. (102) }\end{array}$ & $\begin{array}{l}\text { L. neglec- } \\
\text { tus (69) }\end{array}$ & Both (7) \\
\hline Lasius niger (935) & 79 & $27^{\mathrm{a}}$ & 2 \\
Tetramorium immigrans (613) & $36^{\mathrm{a}}$ & 38 & 3 \\
Tetramorium caespitum (308) & 24 & $6^{\mathrm{a}}$ & 0 \\
Lasius alienus (263) & $11^{\mathrm{a}}$ & $2^{\mathrm{a}}$ & 0 \\
Lasius emarginatus $(203)$ & 21 & 9 & 1 \\
Lasius paralienus $(54)$ & 7 & 1 & 0 \\
\hline
\end{tabular}

Numbers between brackets are the total number of locations where each species occurred

${ }^{\text {a }}$ Represents non-random co-occurrences between Fallopia spp. and native ant species and between $L$. neglectus and native ant species. All were negative co-occurrences (i.e., observed co-occurrences were lower than expected by chance)

to increase the frequency of introduction events enhance secondary spread and affect establishment probabilities, (ii) two climatic variables, i.e., mean annual temperatures and mean annual precipitations, because coarse climate variables affect the distributions of most ant species in including $L$. neglectus (Gippet et al. 2017) and (iii) three variables associated with natural and human-mediated dispersal of the two invasive species (distance to water courses, distance to main roads and distance to roadside embankments). Land cover variables (1.5-m spatial resolution) were obtained from the combination of several GIS resources [within BD TOPO ${ }^{\circledR}$ (2013) IGN], and image processing from SPOT6 images (http://geosud.teledetection.fr). Climatic variables (1-km resolution) were obtained from Bioclim (Hijmans et al. 2005). Distances to rivers, main roads, and embankments (vectorial data) were obtained from BD TOPO ${ }^{\circledR}$ (2013) IGN. Overlap of environmental preferences was investigated using principal component analysis and linear discriminant analysis (R package ade4, Dray and Dufour 2007; adegraphics; Dray et al. 2016; MASS; Venables and Ripley 2002; caret; Kuhn et al. 2016) integrating eight environmental variables. A linear discriminant analysis was performed in order to detect potential sets of variables discriminating between locations where L. neglectus and Fallopia spp. were present. We calculated a Kappa index (Cohen 1960) in order to assess our ability to distinguish between the two groups of locations based on the eight environmental variables used. This index indicates the probability to correctly predict the species occurring at a sampling location knowing the coefficients of linear discrimination for each environmental variable. A low Kappa index value $(<0.7)$ indicates that the environmental preferences of the two invasive species are similar while a higher value indicates different environmental preferences. 


\section{Interactions between $L$. neglectus and $F$. $\times$ bohemica}

In order to investigate reciprocal benefits from the association between L. neglectus and Fallopia spp., we chose two areas (hereafter referred as "experimental areas") where garden ants occur along with $F$. $\times$ bohemica (identified visually using leaf shape), which is the prevalent Fallopia taxon within the urbanized area of Lyon. Experimental area 1 was located in the main water collection site for the Lyon metropolitan area, which comprises two islands of the Rhône River and is forbidden to the public, enabling short- and long-term ecological studies (Fig. S1). This area, measuring $3.75 \mathrm{~km}^{2}$, contained several patches of $F$. $\times$ bohemica and was characterized by spatially heterogeneous densities of L. neglectus and the occurrence of several native species foraging on knotweeds. In this area, we used seven $F$. $\times$ bohemica patches occupying $110-330 \mathrm{~m}^{2}$ and separated by 100-1500 m. Experimental area 2 was located in a restricted military area measuring $16 \mathrm{~km}^{2}$, where we focused on one single patch of $F . \times$ bohemica $\left(1162 \mathrm{~m}^{2}\right)$ completely encompassed within a L. neglectus colony, which was the sole foraging ant species found on knotweeds. These two areas were not part of the 1248 locations sampled during the systematic survey (Fig. 1) and were not used in the co-occurrence analysis to avoid bias.

\section{Nectar collection by L. neglectus}

A nectar-collecting experiment was conducted in April 2011 in experimental area 2 where a colony of L. neglectus exploited a $1162 \mathrm{~m}^{2}$ patch of $F . \times$ bohemica. We chose this knotweed patch because it was the only locality known to us where L. neglectus was the sole species foraging on knotweeds. As our intent was to measure nectar intake by $L$. neglectus, this situation eliminated possible bias by avoiding competition effects with other ant species and confusion with morphologically similar species (e.g., L. niger) when counting and sampling ants. In the field, 59 knotweed stems were filmed for 45 min using a Sony Handycam camera set on a tripod at a distance of $30 \mathrm{~cm}$ from the stems. The number of L. neglectus workers visiting each stem (i.e., ant activity) was recorded. Two mirrors were placed behind the stems to guarantee complete stem monitoring. Ant activity was measured on 20 and $50 \mathrm{~cm}$ high stems $(n=31$ and $n=28$, respectively) at different days and times of day (between 10 a.m. and 6 p.m.). To make reading easier, we expressed ant activity in number of ant visits per stem per hour. Air temperature was recorded at ground level for each filmed stem using a digital thermometer. Air temperatures ranged from 12 to $33.4{ }^{\circ} \mathrm{C}\left(\right.$ mean \pm s.d. $\left.=21.4 \pm 6.5{ }^{\circ} \mathrm{C}\right)$. These values were higher than those recorded by the closest meteorological station available for April 2011 (i.e., Lyon-Bron; average minimum $=9{ }^{\circ} \mathrm{C}$, average maximum $=21^{\circ} \mathrm{C}$, average mean $=15^{\circ} \mathrm{C}$; source: wunderground.com 2017) which is not surprising because the experiments were realized during daytime only and because experimental area 2 is located on the edge of a large dry meadow which is sparsely vegetated in April and thus rapidly heated by sunlight. The relationship between the recorded air temperature $\left({ }^{\circ} \mathrm{C}\right)$ and ant activity for both 20 - and $50-\mathrm{cm}$ stems (as a categorical variable), was tested using a generalized linear model with a Poisson link function and a quadratic effect on temperature. We measured nectar uptake by ants using the method of Paris and Espadaler (2009), which assumes that mass difference between ants heading up and down the stems is due to the nectar collected. Sixty-four stems were sampled: thirty-three $20-\mathrm{cm}$ high shoots and thirty-one $50-\mathrm{cm}$ high shoots. For each stem, one pool of ten ascending and one pool of ten descending workers were weighed $( \pm 0.01 \mathrm{mg}$, Sartorius CPA225D balance), in order to determine the mass of nectar collected at each ant visit. The number of knotweed stems per square meter was counted in nine transects $(1 \mathrm{~m}$ wide by 4-7 $\mathrm{m}$ long) placed within the $1162 \mathrm{~m}^{2}$ patch, in order to extrapolate the total number of stems in the patch. We tested the effect of temperature and plant size on L. neglectus foraging activity using Poisson regression (with quadratic effect for temperature). Using our estimation of ant foraging activity, amount of nectar collected per visit, and number of knotweed stems in the patch, we estimated the amount of nectar collected by the colony during daytime hours $(12 \mathrm{~h}$ a day in April) under the assumption that the colony is able to simultaneously visit all stems in the patch.

\section{F. $\times$ bohemica leaf damage}

A leaf damage survey was conducted in April 2010 in experimental area 1 which is patchily invaded by both $L$. neglectus and $F . \times$ bohemica (Fig. 1). Leaf damage was recorded at six $F . \times$ bohemica patches with different $L$. neglectus abundances (Fig. S2). Knotweed patches were all located near water and woods and their surface ranged from 110 to $330 \mathrm{~m}^{2}$ (Fig. S1, S2). L. neglectus and other ant species abundances were evaluated in each patch using bait sampling between June and September 2009, at temperature between 20 and $25^{\circ} \mathrm{C}$. Baits (honey and tuna) were placed on the ground and located every $4 \mathrm{~m}$ along transects running along and within the knotweed patch (51-92 baits per site). After waiting $1 \mathrm{~h}$, all ant workers feeding at baits were sampled and identified. Ant species composition and abundance might vary among days, month and year, but we assumed that the local spatial distribution of L. neglectus into and around patches should not shift significantly from June-September 2009 to April 2010 as, in our study area, $L$. neglectus is less active in late summer and fall (in comparison with spring and early summer), hibernates during winter and restart its activity in early April (personal observations). 
For each patch, at least $30 \mathrm{~F} . \times$ bohemica stems were sampled (for a total of 189 stems); for each stem all leaves were cut and scanned (for a total of 787 leaves). Foliar surface area was measured using ImageJ (Rasband 2015). For each leaf, we reconstructed the initial leaf shape (undamaged leaf) and then estimated the amount of leaf area lost by subtracting the surface of the scanned leaf from the initial surface (the undamaged surface), which provided an estimation of leaf loss (Kawano et al. 1999). The relationship between the abundance of L. neglectus and leaf damage (measured as leaf area lost) due to herbivory was tested using logistic regressions with random effect on knotweed patch identity and knotweed stem identity (package lme4, Bates et al. 2015).

\section{Results}

\section{Co-occurrence patterns and environmental preferences overlap}

Of the 1248 sampled locations, 102 were invaded by Fallopia spp. and 69 by L. neglectus (respectively, 8.2 and $5.5 \%$ of the sampling locations), but only seven locations $(0.6 \%)$ were invaded by both taxa (Fig. 1; Table 1 ). $L$. neglectus colonies were absent from the eastern part of the studied area while Fallopia spp. was very frequent in this area but almost absent from the southern part of the study area (Fig. 1).

Co-occurrence analysis revealed no significant positive association between Fallopia spp. and L. neglectus (standardized effect size $=0.00112 ; p=0.33$ ). However, L. neglec tus occurrence was negatively correlated with three native species occurrences (L. niger, L. alienus, and T. caespitum). Fallopia spp. occurrence was negatively correlated with two native ant species (L. alienus and T. immigrans). The two first axes of the Principal Component Analysis on environmental variables explained, respectively, 36.8 and $18.3 \%$ of total variability, respectively. The first axis comprised climatic and land cover variables, while the second was mainly correlated to distance to rivers, distance to embankments and percentage of forest cover (Fig. 2, Table S1). In this factorial plane, Fallopia spp. and L. neglectus environmental preferences overlapped but knotweeds showed broader environmental preferences than L. neglectus (Fig. 2). Linear discriminant analysis confirmed that there was no clear separation between locations where L. neglectus and Fallopia spp. were present (Kappa index $=0.42$ ), indicating that the environmental preferences of the two species were not distinguishable based on the eight environmental variables used.
Fig. 2 Principal component analysis scatterplot. Environmental factors (boxed) are represented as vectors; their relative size reflecting their influence (longer lines indicate greater influence) and their direction indicating their correlation to each axis. All symbols represent sampling locations $(n=1248)$; black diamonds are locations with Fallopia spp. present; triangles are locations with L. neglectus present, and gray dots are locations where none of the two species occurred. Ellipses containing $75 \%$ of a species locations are drawn for each species to represent environmental preferences overlap, with the full line ellipse representing knotweed preferences and dotted line ellipse representing $L$. neglectus preferences

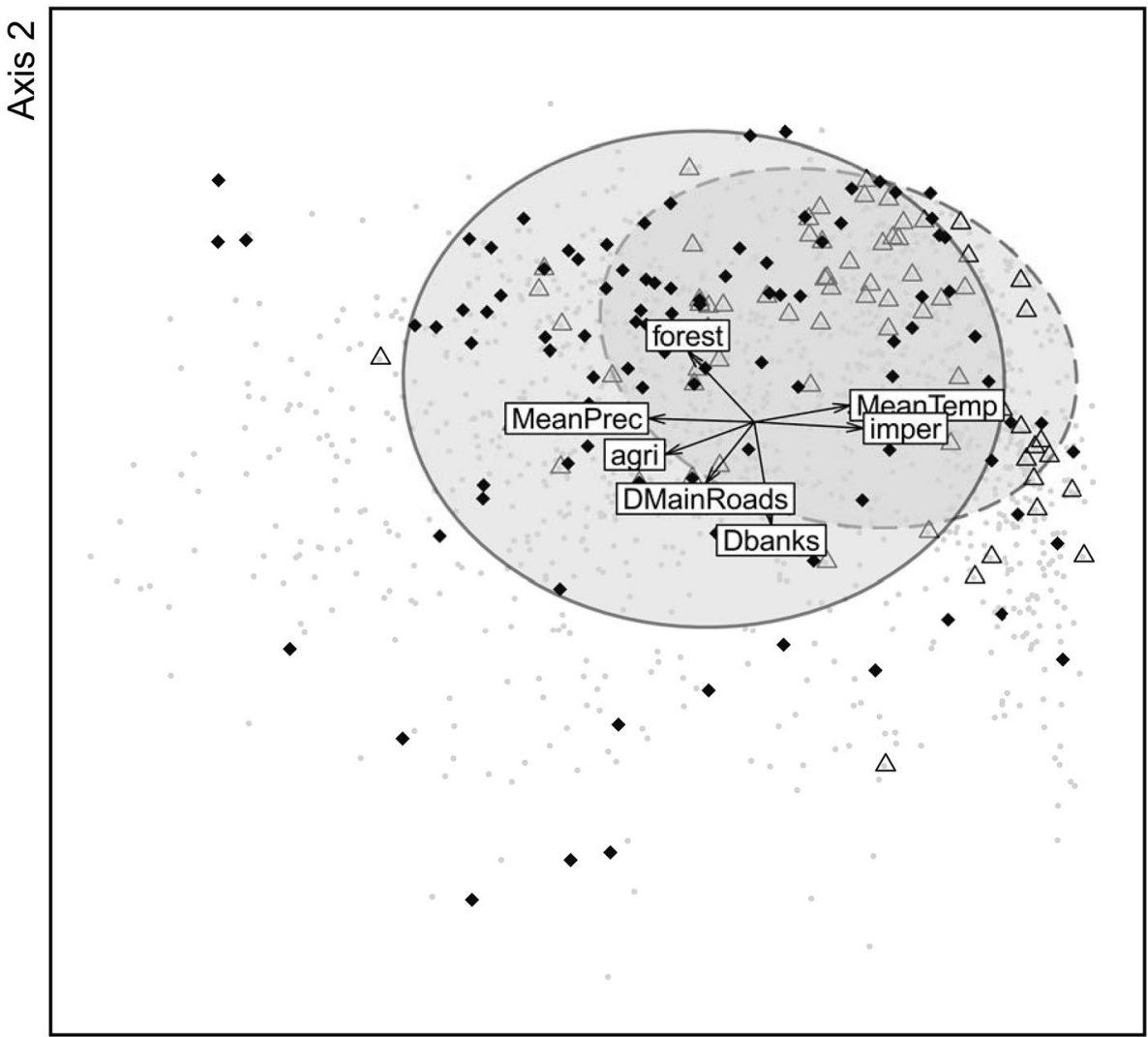

Axis 1 


\section{Interactions between $L$. neglectus and $F$. $\times$ bohemica}

\section{Nectar collection by L. neglectus}

Both plant size [coefficient $(50 \mathrm{~cm}$ stems $) \pm \mathrm{SE}$ : $-0.762 \pm 0.0036 ; p<0.0001)$ and temperature [temperature and (temperature) $)^{2}$ : slope \pm SE: $0.239 \pm 0.0022$ and $-0.0053 \pm 0.0005$, respectively; $p<0.0001$ and $p<0.0001$, respectively] had significant effects on ant activity on $F . \times$ bohemica shoots [explained deviance $=0.38$; df: 56 (null) and 53 (residuals)] (Fig. 3). L. neglectus activity peaked at ca. $24{ }^{\circ} \mathrm{C}$, and there were twice as many ants on $20-\mathrm{cm}$ stems as on $50-\mathrm{cm}$ stems.

We estimated the quantity of nectar collected by $L$. neglectus using average and confidence intervals values of ant activity (71.4 ants visiting one knotweed stem per hour, 95\% CI [54.65; 88.15]), and nectar collected by ant (0.1836 mg of nectar collected per visit, 95\% CI [0.158; $0.21]$ ). We assumed a daytime only foraging activity of $12 \mathrm{~h}$ per day and simultaneous visits to all stems (mean number of stems per $\mathrm{m}^{2}=41.58$, s.d. $=19.4$ ) in the 1162 $\mathrm{m}^{2}$ F. $\times$ bohemica patch. Over April (30 days), L. neglectus workers might therefore collect $150-321 \mathrm{~kg}$ of nectar, (mean $=235.5 \mathrm{~kg}$ ), corresponding to $41,398,422$ daily (12 h) visits of L. neglectus workers in the $1162 \mathrm{~m}^{2}$ knotweed patch $(95 \%$ CI $[31,686,940 ; 51,109,904])$.

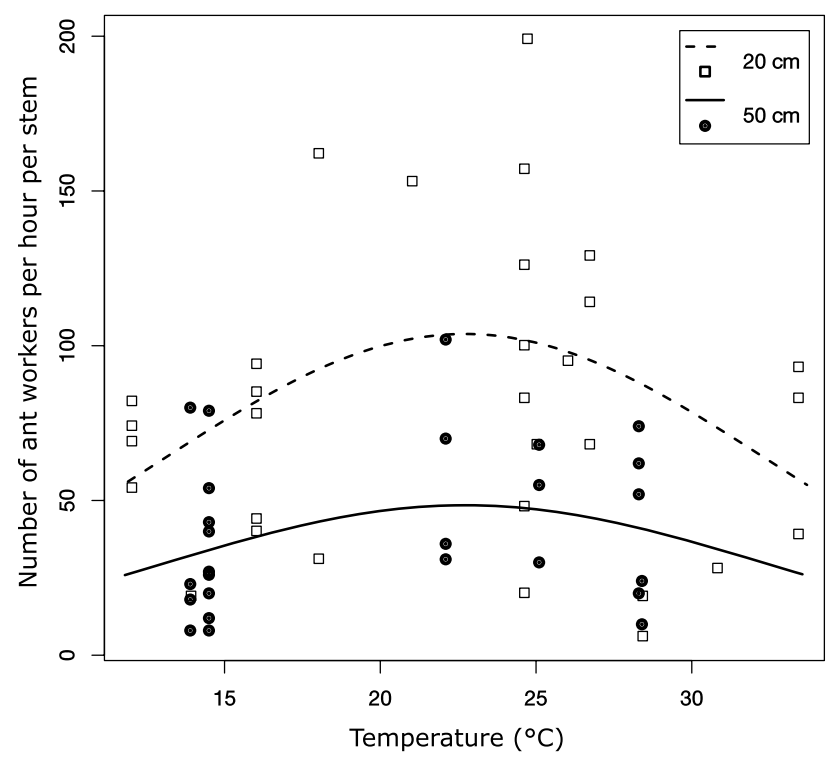

Fig. 3 Quadratic relationship between ant activity (number of workers by stem by hour) and temperature $\left({ }^{\circ} \mathrm{C}\right)$ for both 20 and $50 \mathrm{~cm} \mathrm{~F}$. bohemica stems

\section{F. $\times$ bohemica leaf damage}

Herbivory was low, with a mean \pm s.d. leaf surface loss by stem of $3.1 \pm 17.6 \%$ (ranging from 0 to $34 \%$ ); however, $67.7 \%$ of stems were affected by herbivory. We found no relationship between the proportion of leaf surface lost and L. neglectus or native ant species abundance (no model was better than the null model based on AIC, Fig. S2).

\section{Discussion}

The present study investigated the landscape invasion patterns and potentially beneficial association of two widespread invasive species in Europe: the Japanese knotweed species complex Fallopia spp. and the invasive garden ant L. neglectus. The two taxa did not co-occur more than by random but shared similar environmental preferences in the studied landscape. We showed that Fallopia spp. may constitute a major resource pulse for the invasive ant as $L$. neglectus was shown to collect large amounts of nectar on knotweeds. However, we found no benefit for Fallopia spp. as leaf damage was very low and was correlated to neither L. neglectus nor native ant species abundances.

\section{Co-occurrence patterns and environmental preferences overlap}

That Fallopia spp. and L. neglectus were not more often associated than by random landscape encounter is not altogether surprising, as knotweeds and garden ants are not obligate partners and establish large populations without requiring the presence of the other species. In addition, although they partly share the same dispersal vectors (human-mediated transport), knotweeds and invasive garden ants have different introduction and secondary spread histories. Fallopia spp. were introduced in Lyon in 1860 (F. Piola, personal communication) and knotweeds use multiple modes of dispersal (anemochory, hydrochory, and human-mediated transport; Rouifed et al. 2014), whereas the first occurrence of L. neglectus in the landscape of Lyon was witnessed in 1995 and human-mediated dispersal is the only known process responsible for its secondary spread at landscape scale (Espadaler et al. 2007). This result contrasts with Ness et al. (2013) who found a clear co-occurrence pattern between Fallopia japonica and the European red ant Myrmica rubra (which is invasive in North America). Although not discussed by the authors, in the red ant-knotweed association, the dispersal of both species could be correlated. All 39 sites they surveyed were located along the same river, which could act as a dispersal corridor for both species, with colonizable sites likely similar for both species, because of perturbations such as flooding, to which red ants are highly 
resistant (Arndt et al. 2011), favoring both invasives over natives. In our study area, both knotweeds and garden ants are capable of mutualistic relations with native biodiversity. L. neglectus uses resources from aphids and from the EFNs of native and non-native plants (Paris 2007; Paris and Espadaler 2009), while Fallopia spp. might benefit from the protection of native ant species against defoliators (Kawano et al. 1999; Ness et al. 2013). Both Fallopia spp. and $L$. neglectus are therefore likely to continue to colonize landscapes independently and for this reason, they should cooccur more often in the next decades. In addition, we showed that the two invaders had overlapping environmental preferences at landscape scale, suggesting that a large part of the landscape is likely to be affected by their co-occurrence. The absence of $L$. neglectus colonies in the eastern part of the landscape (Fig. 1) could either result from invasion history, i.e., invasive garden ants could have been introduced near the Rhône valley and not yet been transported eastwards, or from environmental limitations not accounted for in this study, such as microhabitat features (Gippet et al. 2017). Investigating the effects of microhabitat environmental variables on both species' probabilities of presence appears necessary to define the potential spatial co-occurence range of Fallopia spp. and L. neglectus and should be investigated in future studies.

L. neglectus occurrence was negatively associated with the occurrence of three native ant species. This could be the result of either competitive interactions (likely for L. niger, Nagy et al. 2009) or distinct environmental preferences (likely for T. caespitum, Gippet et al. 2017). Differences in environmental preferences could also explain the negative association between Fallopia spp. and two native ant species (L. alienus and T. immigrans) (Table 1).

\section{Interactions between $L$. neglectus and $F . \times$ bohemica}

\section{Nectar collection by L. neglectus}

We showed that $L$. neglectus intensely visited $F . \times$ bohemica shoots. As could be expected, ant activity was a function of temperature but we showed that optimal foraging temperatures for L. neglectus were reached as soon as early April, when knotweed shoots start their growth. Spring is a crucial period for L. neglectus because this species produces its alate gynes and males from April to June, demanding increased access to resources (Van Loon et al. 1990). We also found that short shoots $(20 \mathrm{~cm}$ high) were more visited than tall shoots $(50 \mathrm{~cm}$ high). This corroborates previous studies (Kawano et al. 1999) showing that Fallopia spp. decrease their nectar production when growing, concentrating ant activity on the youngest shoots, which are more vulnerable to herbivory. By extrapolating our measures of L. neglectus foraging activity and nectar uptake by visit, we estimated that garden ants collected $150-321 \mathrm{~kg}$ of nectar per month in the $1162 \mathrm{~m}^{2} \mathrm{~F} . \times$ bohemica patch under study. For comparison, Paris and Espadaler (2009) estimated that garden ants extracted $0.35 \mathrm{~kg}$ (from 0.05 in October to 0.82 in July) of aphid honeydew per holm oak tree per month in 2004, with a total of $2.09 \mathrm{~kg} /$ tree/year; no data on April activity were recorded. The yearly production of a single holm oak, which uses a soil surface of at least $10 \mathrm{~m}^{2}$ (Cointat 1953), therefore barely equates that of a $10 \mathrm{~m}^{2}$ of knotweeds in a single month $(2.35 \mathrm{~kg})$, emphasizing the high productivity of knotweeds and their importance as a temporary early season resource pulse for ants. As extra-floral nectar and aphid honeydew contain similar amounts of carbohydrates (240-304 mg/ml in Fallopia spp., 500-660 mg/ml in Vigna unguiculata, Pate et al. 1985, between 30 and $350 \mathrm{mg} / \mathrm{ml}$ in four species of aphids; Völkl et al. 1999), both food sources are likely to boost colony growth, the production of alate reproductives and, for recently founded $L$. neglectus supercolonies, post-transport survival rates (Lach et al. 2009). While the detailed composition of nectar has been investigated in detail (Roy et al. 2017, but most studies investigated floral nectar), honeydew composition did not receive as much attention, and seems to be highly variable even within a same aphid species (Fisher and Shingleton 2001). The role of amino acids, lipids and secondary metabolites present in nectar and honeydew remains unexplored for ants (Roy et al. 2017). However, in another unicolonial and invasive ant species, the Argentine ant Linepithema humile, the progression of invasion was experimentally favored by placing sucrose feeding stations (Rowles and Silverman 2009), a role possibly played here by knotweed EFNs, showing that sugars are sufficient to induce colony growth. A recent study (Tartally et al. 2016) showed that many European L. neglectus colonies have collapsed. Among several possible causes, depletion of local resources and lack of suitable habitats have been pointed out by the authors. By providing large quantities of nectar, Fallopia spp. could increase the probability of survival of L. neglectus colonies and hence limit collapses in locations were native plant species do not provide such resources. Indeed, as Fallopia spp. growth start in early spring (late March to early April) and young shoots provide nectar as they grow, knotweed patches might constitute one of the few resources available in large quantities at this period of the year.

\section{F. $\times$ bohemica leaf damage}

Our results showed no relationship between leaf damages and abundance of both native and invasive ants. The proportion of leaf surface lost in $F . \times$ bohemica was low $(3.11 \pm 5.97 \%)$ but variable between knotweed patches (between 1 and 6\% depending on the patch, Fig. S2). This variability in herbivory between patches suggests that local 
environmental variations such as microhabitats, arthropod community parameters or knotweed patch history are likely to affect herbivory and should be taken into account in further studies. The low rates of herbivory indicate either that few herbivores were present in the studied area or that ant protection was efficient and equivalent between $L$. neglectus and native species. This observation is similar to the pattern described in Ness et al. (2013), where herbivory was even lower (around 1\%). In Japan, knotweeds are heavily defoliated, despite the presence of native ants (Kawano et al. 1999) which do reduce, but not to the levels recorded here (i.e., 28.5-43.2\% leaf surface loss in Kawano's study in Japan versus $3.1 \%$ in our study in France). Native and invasive ants could however act as environmental barriers by preventing or slowing down the adaptation of native herbivores species to the consumption of Fallopia spp. leaves. Rare, but intense episodes of herbivory could also induce nectar production by the plant, in order to attract ants even outside of the early season where young shoots rise, as is suggested by the results of Ness et al. (2013). While our results suggest that $L$. neglectus presence and abundance do not affect herbivory rates in $F$. $\times$ bohemica, our experiment was not designed to detect small differences and was also subject to variations in time and among patches of microhabitats as well as insect communities. Detecting subtler consequences of $L$. neglectus abundance on knotweeds leaf damages would necessitate exclusion experiments, combined with herbivore introduction, in the field and in the lab.

\section{Conclusion}

From our results, the relationship between garden ants and invasive knotweeds is best described as a commensalitic one, probably benefiting ants without clear benefits for plants. Our study raises a number of issues about the Fallopia spp.-L. neglectus association that should be investigated: (i) the consequences of knotweed occurrence on L. neglectus colony growth rates and impacts, (ii) if Fallopia spp. nectar is a better resource (in terms of quantity or quality) for $L$. neglectus than native EFNs or aphids bearing plants, (iii) if ants prevent or slow the adaptation of native herbivores to the consumption of knotweed leaves, (iv) if the relationship between $L$. neglectus and Fallopia spp. is affected by the ecological context (e.g., herbivores communities composition, availability in water and other food resources, climate). Fallopia spp. were introduced into Europe 100 years before L. neglectus and now occur in much of western Europe (Bailey and Wisskirchen 2004), thus adding potential resources foci for L. neglectus colonies and increasing the likelihood of secondary spread in the future (Cremer et al. 2008; Gippet et al. 2017). While no co-occurrence pattern was documented in our landscape, the broad landscape-level environmental preferences of both invasive species also suggested that occasions for interactions are likely to increase. Our results, although they do not support the hypothesis of an invasional meltdown situation, may stimulate conservation scientists to look further into the association between Fallopia spp. and L. neglectus, notably by comparing ant and plant population growth and impacts when combined versus separate (Kuebbing et al. 2013).

Acknowledgements The study was funded by the Conseil Départemental de l'Isère. This work was supported by the LABEX IMU (ANR-10-LABX-0088) of Université de Lyon, within the program "Investissements d'Avenir" (ANR-11-IDEX-0007) operated by the French National Research Agency (ANR). The authors wish to thank the many students and interns who participated in the extensive sampling and identification of ants over the years. Additional thanks go to M. Amiez, D. Archundia, C. Brunet, M. Demarcy, A. Dumet, A. Grimaud, A. Kong Win Chang E. Nicolay, and L. Mistler who provided essential help in field sampling, experimentation, and data processing. The authors also thank the anonymous reviewers who greatly helped to improve the manuscript.

\section{References}

Aranda-Rickert A, Fracchia S, Yela N, Marazzi B (2017) Insights into a novel three-partner interaction between ants, coreids (Hemiptera: Coreidae) and extrafloral nectaries: implications for the study of protective mutualisms. Arthropod Plant Interact. https://doi. org/10.1007/s11829-016-9487-z

Arndt E, Grunert H, Schuler J (2011) Influence of inundation pattern on the epigaean ant fauna in a European floodplain forest complex (Hymenoptera: Formicidae). Entomol Gener 33:39-48

Bailey JP, Conolly AP (2000) Prize-winners to pariahs - a history of Japanese Knotweed s.l. (Polygonaceae) in the British Isles. Watsonia 23:93-110

Bailey JP, Wisskirchen R (2004) The distribution and origins of Fallopia $\times$ bohemica (Polygonaceae) in Europe. Nord J Bot 24:173-199

Bailey JP, Bímová K, Mandák B (2009) Asexual spread versus sexual reproduction and evolution in Japanese Knotweed s.l. sets the stage for the "Battle of the Clones". Biol Invasions 11:1189-1203

Bates D, Maechler M, Bolker B, Walker S (2015) Fitting linear mixedeffects models using lme4. J Stat Softw 67:1-48

Bertelsmeier C, Courchamp F (2014) Future ant invasions in France. Environ Conserv 41:217-228

Cohen J (1960) A coefficient of agreement for nominal scales. Educ Psychol Meas 20:37-46

Cointat M (1953) Surface terrière des taillis de chêne vert. Revue forestière française 12:829-831

Cremer S, Ugelvig LV, Drijfhout FP et al (2008) The evolution of invasiveness in garden ants. PLoS ONE 3:e3338

Decrane LPR, Akeroyd JR (1988) Generic limits in Polygonum and related genera (Polygonaceae) on the basis of floral characters. Bot J Linn Soc 98:321-371

Djeddour DH, Shaw RH, Evans HC, Tanner RH, Seier M (2008) Could Fallopia japonica be the first target for classical weed biocontrol in Europe? In: Julien MH, Sforza R, Bon MC, Evans HC, Hatcher PE, Hinz HL, Rector BG (eds) Proceedings of the XIIth International Symposium on Biological Control of Weeds. CAB International, Wallingford, pp. 463-469

Dray S, Dufour A (2007) The ade4 package: implementing the duality diagram for ecologists. J Stat Softw 22:1-20 
Dray S, Siberchicot A, Thioulouse J, Julien-Laferrière A (2016). adegraphics: An S4 lattice-based package for the representation of multivariate data. $\mathrm{R}$ package version 1.0-5

Espadaler X, Tartally A, Schultz R, Seifert B, Nagy C (2007) Regional trends and preliminary results on the local expansion rate in the invasive garden ant, Lasius neglectus (Hymenoptera, Formicidae). Insectes Soc 54: 293-301

Fisher MK, Shingleton AW (2001) Host plant and ants influence the honeydew sugar composition of aphids. Funct Ecol 15:544-550

Gippet JMW, Mondy N, Diallo-Dudek J, Bellec A, Dumet A, Mistler L, Kaufmann B (2017) I'm not like everybody else: urbanization factors shaping spatial distribution of native and invasive ants are species-specific. Urb Ecosyst 20:157-169

Griffith DM, Veech JA, Marsh CJ (2016) Co-occur: probabilistic species co-occurrence analysis in R. J Stat Softw 69:1-17

Henriksson A, Wardle DA, Trygg J, Dielh S, Englund G (2016) Strong invaders are strong defenders-implications for the resistance of invaded communities. Ecol Lett 19:487-494

Hijmans RJ, Cameron SE, Parra JL, Jones PG, Jarvis A (2005) Very high resolution interpolated climate surfaces for global land areas. Int J Climatol 25:1965-1978

Infoclimat.fr (2016) http://www.infoclimat.fr/stations-meteo/climatomoyennes-records.php?staid $=07480 \&$ from $=1981 \&$ to $=2010 \&$ re direct $=1$. Last Accessed 25 Jan 2016

Jackson M (2015) Interactions among multiple invasive animals. Ecology 96:2035-2041

Kawano S, Azuma H, Ito M, Suzuki K (1999) Extrafloral nectaries and chemical signals of Fallopia japonica and Fallopia sachalinensis (Polygonaceae), and their roles as defense systems against insect herbivory. Plant Spec Biol 14:167-178

Koptur S (1992) Extrafloral nectary-mediated interactions between insects and plants. In: Bernays E (ed) Insect-plant interactions. CRC Press, Boca Raton, 81-130

Kuebbing SE, Nuñez MA (2015) Negative, neutral, and positive interactions among nonnative plants: patterns, processes, and management implications. Glob Change Biol 21:926-934

Kuebbing SE, Nuñez MA, Simberloff D (2013) Current mismatch between research and conservation efforts: the need to study cooccurring invasive plant species. Biol Conserv 160:121-129

Kuhn M. Contributions from Wing J, Weston S, Williams A, Keefer C, Engelhardt A, Cooper T, Mayer Z, Kenkel B, the R Core Team, Benesty M, Lescarbeau R, Ziem A, Scrucca L, Tang Y, Candan $C$ (2016). caret: classification and regression training. $R$ package version $6.0-70$

Lach L (2007) A mutualism with a native membracid facilitates pollinator displacement by argentine ants. Ecology 88:1994-2004

Lach L, Hobbs RJ, Majer JD (2009) Herbivory-induced extrafloral nectar increases native and invasive ant worker survival. Popul Ecol 51:237-243

MacNeil C, Dick JT (2014) The enemy of my enemy is my friend: intraguild predation between invaders and natives facilitates coexistence with shared invasive prey. Biol Lett 10:20140398

Marazzi B, Bronstein JL, Koptur S (2013) The diversity, ecology and evolution of extrafloral nectaries: current perspectives and future challenges. Ann Bot-London 111:1243-1250

Nagy C, Tartally A, Vilisics F et al (2009) Effects of the invasive garden ant. Lasius neglectus Van Loon, Boomsma and András-Falvy, 1990 (Hymenoptera: Formicidae), on arthropod assemblages: pattern analyses in the type supercolony. Myrmecolog News 12:171-181

Ness JH, Morales MA, Kenison E, Leduc E, Leipzig-Scott P, Rollinson E, Swimm BJ, von Allmen DR (2013) Reciprocally beneficial interactions between introduced plants and ants are induced by the presence of a third introduced species. Oikos 122:695-704

Paris CI (2007) Above-belowground effects of the invasive ant Lasius neglectus in an urban holm oak forest, $\mathrm{PhD}$ thesis. Universitat Autonoma de Barcelona, Barcelona

Paris CI, Espadaler X (2009) Honeydew collection by the invasive garden ant Lasius neglectus versus the native ant $L$. grandis. Arthropod-Plant Int 3:75-85

Pate JS, Peoples MB, Storer PJ, Atkins CA (1985) The extrafloral nectaries of cowpea (Vigna unguiculata (L.) Walp. II. Nectar composition, origin of nectar solutes, and nectary functioning. Planta $166: 28-38$

R Core Team (2015). R: a language and environment for statistical computing. R Foundation for Statistical Computing, Vienna. https://www.R-project.org/

Rasband WS, ImageJ U.S. National Institutes of Health, Bethesda, Maryland, USA, http://imagej.nih.gov/ij/ (1997-2015)

Rouifed S, Piola F, Spiegelberger T (2014) Invasion by Fallopia spp. in a French upland region is related to anthropogenic disturbances. Basic Appl Ecol 15:435-443

Roura-Pascual N, Bas JM, Thuiller W, Hui C, Krug RM, Brotons L (2009) From introduction to equilibrium: reconstructing the invasive pathways of the Argentine ant in a Mediterranean region. Global Change Biol 15:2101-2115

Rowles AD, Silverman J (2009) Carbohydrate supply limits invasion of natural communities by Argentine ants. Oecologia 161:161-171

Roy R, Schmitt AJ, Thomas JB, Carter CJ (2017) Nectar biology: from molecules to ecosystems. Plant Sci 262:148-164

Schultz R, Seifert B (2005) Lasius neglectus (Hymenoptera: Formicidae) a widely distributed tramp species in Central Asia. Myrmecol Nachr 7:47-50

Seifert B (2007) Die Ameisen Mittel- und Nordeuropas. Lutra Verlagsund Vertriebsgesellschaft, Tauer, p. 368

Simberloff D, Von Holle B (1999) Positive interactions of nonindigenous species. Invasional Meltdown? Biol Invasions 1:21-32

Tartally A, Antonova V, Espadaler X, Csősz S, Czechowski W (2016) Collapse of the invasive garden ant, Lasius neglectus, populations in four European countries. Biol Invasions 18:3127-3131

Ugelvig LV, Drijfhout FP, Kronauer DJC, Boomsma JJ, Pedersen JS, Cremer S (2008) The introduction history of invasive garden ants in Europe: integrating genetic, chemical and behavioural approaches. BMC Biol 14:1-14

Van Loon AJ, Boomsma JJ, Andrasfalvy A (1990) A new polygynous Lasius species (Hymenoptera: Formicidae) from central Europe. I. Description and general biology. Insect Soc 37:348-362

Veech (2013) A probabilistic model for analysing species co-occurrence. Glob Ecol Biogeogr 22: 252-260

Venables WN, Ripley BD (2002) Modern applied statistics with S. 4th edn. Springer, New York. ISBN 0-387-95457-0

Vitousek PM, Mooney HA, Lubchenco J, Melilo JM (1997) Human domination of Earth's ecosystems. Science 277:494-499

Völkl W, Woodring J, Fischer M, Lorenz MW, Hoffmann KH (1999) Ant-aphid mutualisms: the impact of honeydew production and honeydew sugar composition on ant preferences. Oecologia 118:483-491

Wunderground.com (2017) https://www.wunderground.com/history/airport/LFLY/2011/4/1/CustomHistory.html?dayend=31 $\&$ monthend $=4 \&$ yearend $=2011 \&$ req_city $=\&$ req_state $=\&$ req statename $=\&$ reqdb.zip $=\&$ reqdb. magic $=\&$ reqdb. $w m o=\& M R=1$. Last Accessed 7 Oct 2017 